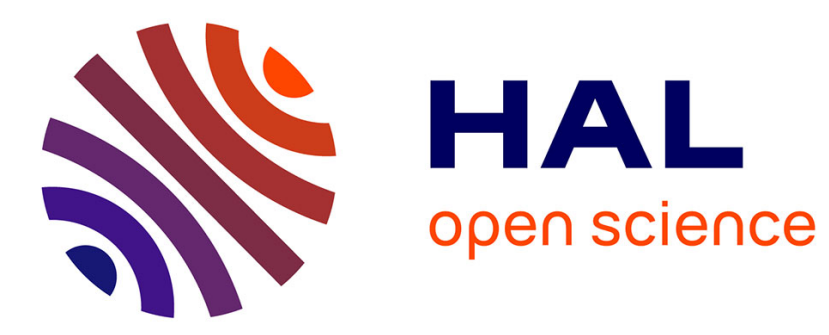

\title{
Life in the shadow of the media
}

Darrin Hodgetts, Andrea Hodgetts, Alan Radley

\section{To cite this version:}

Darrin Hodgetts, Andrea Hodgetts, Alan Radley. Life in the shadow of the media. European Journal of Cultural Studies, 2006, 9 (4), pp.497-516. 10.1177/1367549406063166 . hal-00571508

\section{HAL Id: hal-00571508 \\ https://hal.science/hal-00571508}

Submitted on 1 Mar 2011

HAL is a multi-disciplinary open access archive for the deposit and dissemination of scientific research documents, whether they are published or not. The documents may come from teaching and research institutions in France or abroad, or from public or private research centers.
L'archive ouverte pluridisciplinaire HAL, est destinée au dépôt et à la diffusion de documents scientifiques de niveau recherche, publiés ou non, émanant des établissements d'enseignement et de recherche français ou étrangers, des laboratoires publics ou privés. 


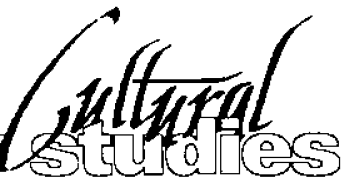

Gopyright 02006 SAGE Publications London, Thousand Oaks ck and New Delhi

Vol 9(4) 497-516; 1367-5494

DOI: $10.1177 / 1367549406063166$ WWW sagep ublications.com

\title{
Life in the shadow of the media
}

Imaging street homelessness in London

Darrin Hodgetts and Andrea Hodgetts

University of Waikato

\section{Alan Radley}

Loughborough University

\begin{abstract}
Media images pervading everyday life often reproduce inequitable social relations that adversely affect the lives of vulnerable people. This article explores the influence of media representations

of homelessness as a source of characterizations that are used by homeless people when representing themselves. To do this, it draws on life narrative interviews, photographic exercises and photo-based discussions with 12 single rough sleepers from London. It documents how participants both reproduce common media storylines foregrounding their differences from housed people and emphasizes aspects of their lives that do not feature in media portrayals, but which invoke their 'normality'.
\end{abstract}

K EYWORDS audience, community, estrangement, homelessness, media

Today, society is saturated with media providing regular commentaries on social concerns, diagnosing social relationships and characterizing marginalized groups. In response, scholars have proposed that if we are serious about fostering social justice then we must address the power of the media to identify and frame public concerns and relationships (Champaign, 1999; Couldry and Curran, 2002). With such issues in mind, we previously interrogated characterizations of homeless people across 10 years of Independent Television News (ITN) reports and considered the implications of these representations for the domicile public (Hodgetts et al., 2005). ITN items did more than transmit information, including the findings of the latest research into homelessness; items shaped such information in a manner that worked to limit homeless people's relationships with domicile citizens and their participation in society. Homeless people were portrayed as occupying another world distinct from the community 
of housed taxpayers, with whom 'vagrants' were only depicted interacting when engaged in prescribed activities such as begging, theft or prostitution. The following extract from a recent newspaper article ('Street Life Stuck in Victorian Era', 2005) - outlining key findings from research conducted for the charity St Mungo's into the health of homeless people - typifies the tendency to characterize 'the homeless' according to the features of their lives that foreground 'what they lack':

Ailments as a direct result of sleeping rough affect 29 per cent of homeless people and include bronchitis, pneumonia and trench foot, as well as repository and cardiovascular conditions. The charity believes that the Government should set up a scheme to bring doctors into homeless hostels, as fewer than one in three of those who need treatment actually receive it, reports Inside Housing.

This would help to tackle ill-health among the homeless and would save money by cutting down on the number of visists made by the home-less to accident and emergency departments. ('Street Life Stuck in Victorian Era', 2005)

This extract relies upon a common news media characterization of homeless people as being diseased, passive, voiceless and overly reliant upon charitable assistance and management. It reflects the depiction of 'vagrants' as one-dimensional bearers of social disadvantage whose problems are to be explained, prevented and cured by charitable organizations, health professionals and the government. Homeless people are rarely cast as active citizens who have a right to participate in solutions and their lives are overwhelmingly articulated through constructed dialogue between charity and governmental representatives and health professionals (see Fiske, 1999).

Such research into media representations of homelessness attests to the contradictory, shallow and highly-selective nature of media characterizations of homeless people, often promoting oppositional relationships between 'those' homeless people and 'us' the domicile public (Min, 1999; Sibley, 1995; Snow and Mulcathy, 2001). It reflects how media coverage often operates to fix boundaries of identity between groups (see Anderson, 1991; Sibley, 1995). In this article we will document how such patterns in media representations of homelessness relate to the self-representational practices of rough sleepers and their actual relationships with members of local domicile communities. In the process we redress the lack of media research into the experiences of marginalized subjects of media representations.

Despite being ever-present in contemporary urban landscapes and often pervading media landscapes, homeless people are rarely given the opportunity to frame their own experiences, relationships or public images. In response to this situation media scholars have argued that: 'It is essential to allow the homeless to describe their conditions in their 
own discourses to provide a more accurate and balanced depiction of the homeless' (Min, 1999: viii). Although this is a noble sentiment, it may be misguided. Groups who are marginalized cannot simply locate themselves within their own discourses. Homeless people face the dilemma of being compelled to act in accordance with the expectations of more powerful groups who name and define 'the homeless'. Often, media coverage regarding such deprived groups does not attend to the perspectives of the marginalized

because their voices are particularly difficult to hear. They are spoken of more than they speak and when they speak to the dominant group, they tend to use a borrowed discourse, the very one the dominant offer about them.

(Champaign, 1999: 51)

Partially in response to such imbalances in symbolic power (Couldry and Curran, 2002) surrounding the construction of homelessness, researchers have established the importance of homeless peoples' personal biographies for revealing how social and symbolic structures influence personal lives and for evaluating services (Boydell et al., 2000; Clapham, 2003). Such research has extended our knowledge of how homeless people view themselves and their place in the world. We know that in addition to the loss of material comforts, homeless people experience a loss of a legitimate place in society and the rights and privileges that accompany citizenship (Sibley, 1995). Often, homeless people are outcast as 'strangers' who do not belong to 'our' domicile communities (Jarvinen, 2003; Simmel, 1908). When cast as overly dependent 'bag ladies' or 'beggars', homeless people can be accused of being a burden and out of place. They become strangers whose lives are subject to 'constant scrutiny and critique, without being allowed to pass judgment on their judges' (Jarvinen, 2003: 218). These individuals become 'untouchables' in our midst with whom domicile citizens often avoid making eye contact, perhaps because the very presence of 'vagrants' can threaten our sense of society as being fair and just.

It is our contention that these processes of estrangement occur both through face-to-face interactions and the mass communication systems pervading today's metropolis. Reports offering 'the homeless' as strangers infiltrate the fabric of face-to-face events (Champaign, 1999), such as when members of the domicile public feel compelled to give to beggars or avoid vagrants. Like ripples in a pool, on entering social dialogue fragments of these media representations take on a life of their own, moving out through society and into lifeworlds (Couldry, 2001), often sanctioning the power of domicile groups to exclude homeless people from civic participation and public spaces (see Atkinson, 2003; Sibley, 1995). Contemporary cultural theory regarding the processes of mediation in daily life (Silverstone, 1999) is essential for researching such processes because it allows us to 
reframe the interactions between ourselves, cultural institutions and other social actors as being central to the routine processes through which contemporary life is conducted (Couldry, 2004). It raises questions such as: how do homeless cultures and daily practices evolve within cityscapes inflected by media representations of homelessness? What are the wider consequences of media frames for social relationships and power? Such questions move this article beyond the tendency in research to treat analyses of media representations and life narratives as separate domains. After all, if media do provide many of the communal resources through which people make sense of their situations and interactions with others, then we need to explore the ways in which media representations are taken up within the lives of homeless people (Clapham, 2003). Thus, we can combine an interest in media-saturated culture and everyday life or experience (Couldry, 2004). This is necessary because ready-made media stories contain assumptions about what it means to be a legitimate member of society and how one should respond to adversity (Champaign, 1999). Exploring rough sleeper accounts as partial reflections of their ongoing engagements with media representations provides insights into the role of symbolic power in shaping the biographies and daily practices of members of arguably the most marginalized group in British society.

\section{The present study}

Visual and verbal methods were used to explore practices through which people who sleep rough make sense of their lives in a media saturated metropolis, London. Twelve participants (nine male and three female) ranging in age from 31 to 60 years took part in life-narrative interviews, photographic exercises and follow-up discussions of their photographs between 9 September and 15 November 2002. ${ }^{1}$ As part of a larger project conducted in partnership with London-based charities, the authors worked with experienced community workers from the recruitment sites to conduct the project in a manner sensitive to the situations and needs of participants. Fieldwork was conducted over a three-month period prior to the formal data collection period in order to 'get a feel' for the local scene and to orientate the research (see Radley et al., 2005).

Generally, the research was designed to reveal links between selfunderstandings, interpersonal relationships, media representations and material life circumstances. It was influenced by the theoretical work of Blumler (1969), who proposed that understanding people's social worlds requires an engagement with the meanings that people impute to the objects, spaces, places and actors that inhabit their lifeworlds. In particular, it took up the idea that social problems do not exist independently as social arrangements devoid of processes of collective definitions shaping mundane social interactions. Inspired by this work, it explored the collective meanings, interactions and real-life experiences of the participants 
by encouraging them to show us their world as well as tell us about and interpret it (Radley et al., 2005).

We were mindful of criticisms of ethnographic studies of homeless people that have been accused of adopting an innocent ethnography that serves only to perpetuate assumptions of the homeless as 'Other' (Madden, 2003). By offering the participants a camera to picture their world, we gave them the opportunity to 'turn upon' their environment and to provide an account of how and why they did so. These accounts often included mention of structural and ideological issues pertaining to the imaging of homelessness, particularly in the mass media, so that we were able to see how these issues were adapted or refused by the participants involved. With respect to the participants, this methodology highlighted the way that their (and hence our) knowledge about homelessness is mediated. This is important in the context of understanding how ideas about homelessness are perpetuated, and indeed the part played in this by homeless people themselves. We sought to examine the degree to which participants utilized these assumptions and how they served them in their attempt to survive under these conditions. Our focus was on how participants see through their photographs and verbal reflections to events, relationships and practices that typify or give meaning to their lives on the street. This involved moving beyond the description of specific photographs, transcripts or depicted instances to broader observations about the ways in which social conditions and relationships are rendered meaningful (Fiske, 1999).

\section{Media characterizations and accounts of one's own situation}

People often consume media images in domestic and work settings or while commuting between such spaces. Media scholars have produced a wealth of knowledge about these spaces. Although homeless people are excluded predominantly from such spaces they also engage with media on a daily basis. Scholars know virtually nothing about their consumption practices. We begin with participants' recollections of media representations of homelessness and recount the ways in which these provide communal memories that are referred to when homeless people piece together their own lives. Such a focus extends existing understandings of the restraints on the efforts of marginalized people to be seen and heard.

The centrality of media to daily survival on the streets became abundantly clear when we repeatedly observed rough sleepers listening to the radio or reading the newspaper under the light of a shop window in the early hours of the morning. This centrality is epitomized when participants brought small radios or newspapers with them into the interview setting. When talking about 'the basics in life', participants invoked media 
as a means of social participation and 'keeping up with events'. In describing his basic equipment for street life, James identified a 'sleeping bag', 'big raincoat' and 'little stereo'. Other participants talked about reading newspapers when sleeping rough and watching television when spending time in hostels. The former includes 'a free one called the Metro. When I used to go over to Victoria, that was the first thing I used to do was pick a Metro up" (Dave). Like all of 'us', homeless people carry a legacy of media use through which they learn about and assign meaning to social concerns, including homelessness.

The influence of this legacy is evident when at some point in the formal interviews all the participants reflected on media typecasting of the homeless" as pitiful examples of humanity who are different from "normal people', 'are dirty', 'don't wash' and 'sleep in doorways'. Several participants went so far as to visually reproduce such 'bounded' characterizations identified by their deviance from the 'dominant' (Sibley, 1995) and then interrogate the partial understandings that these photographs gave by providing further context which added features to the stranger depicted. For example, John took a photograph (Figure 1) and stated:

I just went over Waterloo and started taking some of my friends and people I know... Well, all they domicile people see us as is dirty old drunks. They don't see the person... Appearances make everything, don't they ... These are homeless people with lives and domicile people just miss all that when they see from the outside.

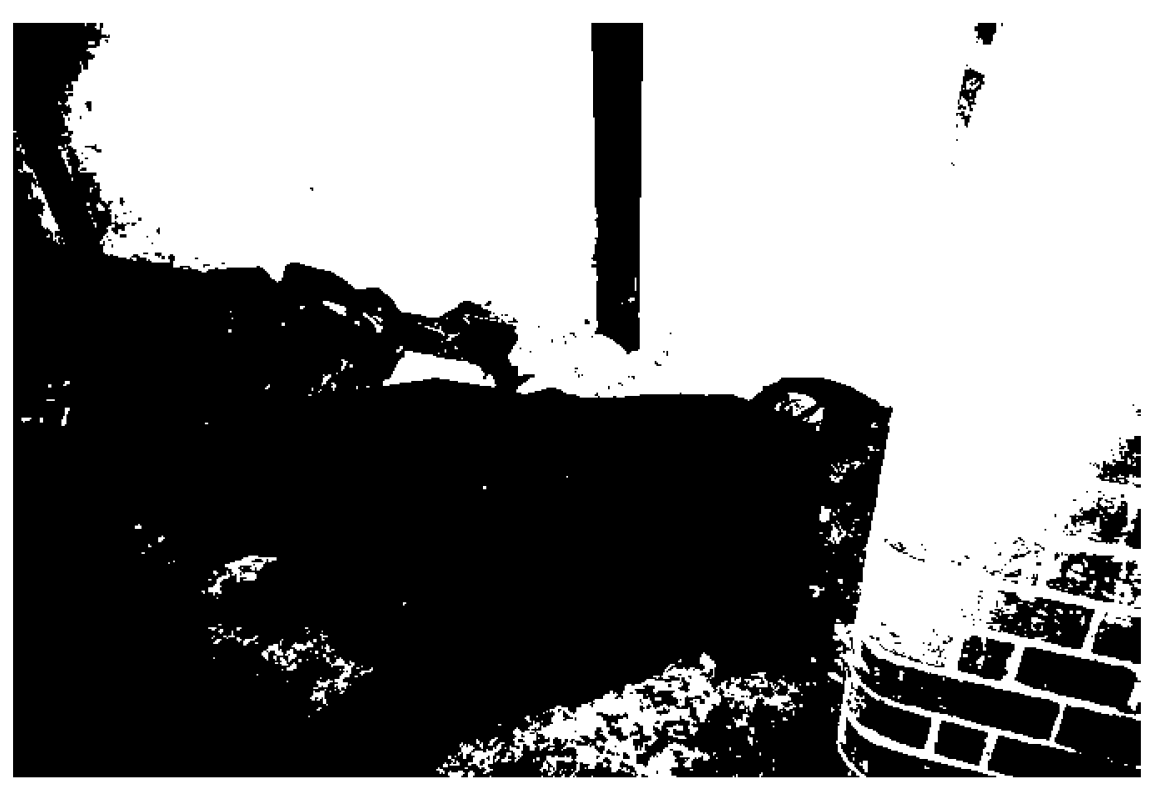

Figure 1 Participant replication of typical news establishing shots depicting the homeless' 
Images of faceless strangers pervade media reports and are used often as establishing shots to 'set the scene' for an investigation of homelessness. Departing from media framing, our participants contextualized such images in ways that personalize those depicted as having stories beyond the features of the rough-sleeping stranger. John went on to discuss the various people lying behind the sleeping bags and his relationships with them. In the process these people were no longer rendered faceless manifestations of an 'estranged' category. They were presented as friends and neighbours.

Often, media imaging processes were invoked as a common reference point from which participants could question what they perceived to be narrow public deliberations regarding homelessness. For example, John questioned whose interests were served by the emphasis on charitable giving warranted by the use of pitiful images of isolated individuals, particularly at Christmas time:

It's 'look at those sad homeless. Look how cold and lonely they're' . . 'Don't you feel sorry for them?' . . Look at what wonderful things we're charities doing'... Well, it's what the media want to represent, innit ... What's it now, September, right? Now watch in the next month, they're gonna go, oh 'Crisis at Christmas', 'we help the homeless', all that and then the rest of the year, 'forget about it'. They don't want to know ... just publicity. They love it.

Here, John invokes the partial nature of media characterizations which are designed to meet the documented needs of the domicile majority to engage in seasonal patterns of sympathy towards less fortunate people. This is reflected in a drastic rise in the number of media reports on homelessness in the build-up to Christmas and a rapid decline from January (Hodgetts et al., 2005). Mark takes further this issue of the seasonal patterning of sympathy during the season of goodwill:

I think some of them are trying to get a message over, like they care. If they could do more, they would. But I don't think they can. I think it's just all talk to make themselves look good in front of all the cameras... That they're doing something. 'Cos if they was gonna do something they would have done it by now.

Despite the overtly critical orientation taken in such extracts, the reproduction of such images reflects the influence of the media in the lives of homeless people. Our participants cannot ignore how they are represented by charitable organizations and journalists. As Couldry writes:

In a world where, for most people, media attention - being publicly listened to - is extremely scarce, tactical challenges to that inequality are inevitably local; they work along the border zones of media geography, playing with its boundaries and rituals of exclusion. (2001: 148)

It is such border work that warrants further consideration. 
When reproducing and then contesting common media characterizations, the participants often referred to the difficulties in displaying alternative images that represented their own lives more fully. In the process they differentiated themselves from homeless characters who appear in the media (Dewdney et al., 1994). They worked to contextualize common media depictions in a manner that qualified any relevance to their own lives. The legacy of media images in the participants' efforts to give meaning to their situations and experiences became particularly evident when several referred to instances where they had consumed media images of homelessness prior to their becoming homeless:

This stuff has got to be a certain amount of emotional pull on the heartstrings. It's got to be a certain amount of action to get people's interest. So how [do] you make a life [story] about a homeless person [or] a documentary about someone interesting. I have watched Cathy Come Home... It's a couple back in the 1960 s. And then there's the inebriate woman, she was drinking all the time. I forgot the actress's name. But when I watched those I wasn't homeless, they were interesting, I felt sorry for Cathy Come Home. I felt very sorry for their relationship... I just felt, wow, alcohol all the time.

Here, Phillip raises the example of the documentary Cathy Come Home (Ken Loach, 1966) in a manner that reflects the way in which engagements with media portrayals become reference points or communal memories used to conceptualize one's own situation and relationship with the domicile public. It is through a tension between a sense of needing to comply with media framing and the desire to represent oneself on one's own terms that Phillip explores what it means to be homeless. Continuing with the points raised regarding media representations and the expectations of members of the domicile public, Phillip reflects on the relationship between the photographs that he produced and those produced by journalists:

It's their own voices, homeless people in the media, but it's not like how you and I are talking. It's, like, the journalists already know the subject matter is going to be boring, so let's dress it up ... Let's grab the audience we want... The media doesn't go out and show it as it is. They show the bits that they think is going to be OK ... We're getting the one that's presentable for TV viewing. You're not getting a full picture ... When I was taking these photographs I thought, well, when Darrin gets these developed he's going to think, 'These are bleed'n boring! But no, he's doing this homeless thing, what else can I show you?' . . . How do you make a film, a book or take photographs about boredom, mundane things and make them interesting at the same time, a contradiction in terms... How do you present it?

Phillip's efforts to represent his own lived experiences necessitated an engagement with the ways in which homeless people are represented by the media. This engagement opens up a space where Phillip speculates as to why homelessness is overdramatized and who gets to frame the issue of 
homelessness. He articulates an understanding of the function of the media's reliance on dramatic representations of poverty, while also questioning the limited vision promoted by such images. In reflecting on these issues, Phillip demonstrates a desire to communicate the mundane nature of his everyday life. This is an important feature because throughout, the participants' photographs of mundane, 'boring' and inherently 'pointless' aspects of street life were presented as being central to experiences of homelessness.

Briefly, these extracts reflect how media depictions contribute to homeless people experiencing pressure to represent themselves in ways that are likely to attract and maintain a domicile audience. Pressures either to conform to the fleeting features expected of these strangers or to develop more personal images have been explored elsewhere (Snow and Anderson, 1993), but not directly in relation to the media. The metaphor of a mask of homelessness is appropriate in unpacking the influence of the media as resources for self-characterizations. There is a public face of homelessness often circulated via the media that can be worn in some contexts where people play the homeless character. This is the case when participants talk about or photograph people sleeping in doorways, getting drunk or begging. Participants are aware of the currency of these images and their association with domicile public expectations. Despite voicing criticisms of the need to appropriate such images, the very act of acknowledging their currency reproduces their legitimacy and relevance to the representation of homelessness. This is an ongoing dilemma for marginalized groups who may wish to communicate alternative images that challenge existing processes of symbolic power. However, in order to get their message across they must engage with the symbolic resources imposed by more dominant social groups (Champaign, 1999).

\section{Searching for community beyond media characterizations}

The media portray homeless people as miserable, isolated, diseased, dependent and troublesome strangers who lack friends and purpose (Min, 1999). These are people residing outside of 'normal' social enterprise and relationships (Hodgetts et al., 2005). In response to such pervasive characterizations our participants' references to community participation can be interpreted as claims to normality and humanity. Below we explore the basis for these claims in relation to the participants' articulations of searches for two forms of community. First, the participants seek membership of homeless communities, exemplified with reference to participation in groups of beggars or drinking schools that mark homeless people as distinct from the domicile community. Second, the participants seek participation in local domicile communities through casual engagements with 
local residents that they meet in parks and local businesses. In seeking meaningful conversations with such people, the participants claim status as local residents and attempt to become one of 'us'. We illustrate how the meanings that participants impute upon spaces and interactions within these communities are anchored in, but extend well beyond, common expectations promoted via media representations. In the process, we show how homeless people may work to reposition themselves as active citizens rather than as inferior 'strangers'. This, in turn, supports a discussion of the fragility of the participant's efforts to construct a sense of self and place from the margins of society and in the shadow of media-cultivated accusations.

For those seeking community with other homeless people, drinking and begging were depicted as communal practices that facilitated regular social interactions, reciprocity and friendship. Photographs often depicted homeless people as more than miserable victims of circumstance or 'angry old drunks'. They were depicted as friends who had fun while participating with others in group settings. The following photograph (Figure 2) exemplifies such community ties in the form of a drinking school (Archard, 1979). It is discussed by Linda as follows.

That's when I sit with my friends in the morning, like. . . That's where I go and associate... We've got a day centre here that helps us, provides food, hot drinks and as you can see, everyone drinks alcohol... We all live on the streets and we're homeless and we associate with each other ... It's good to have friends to have fun with.

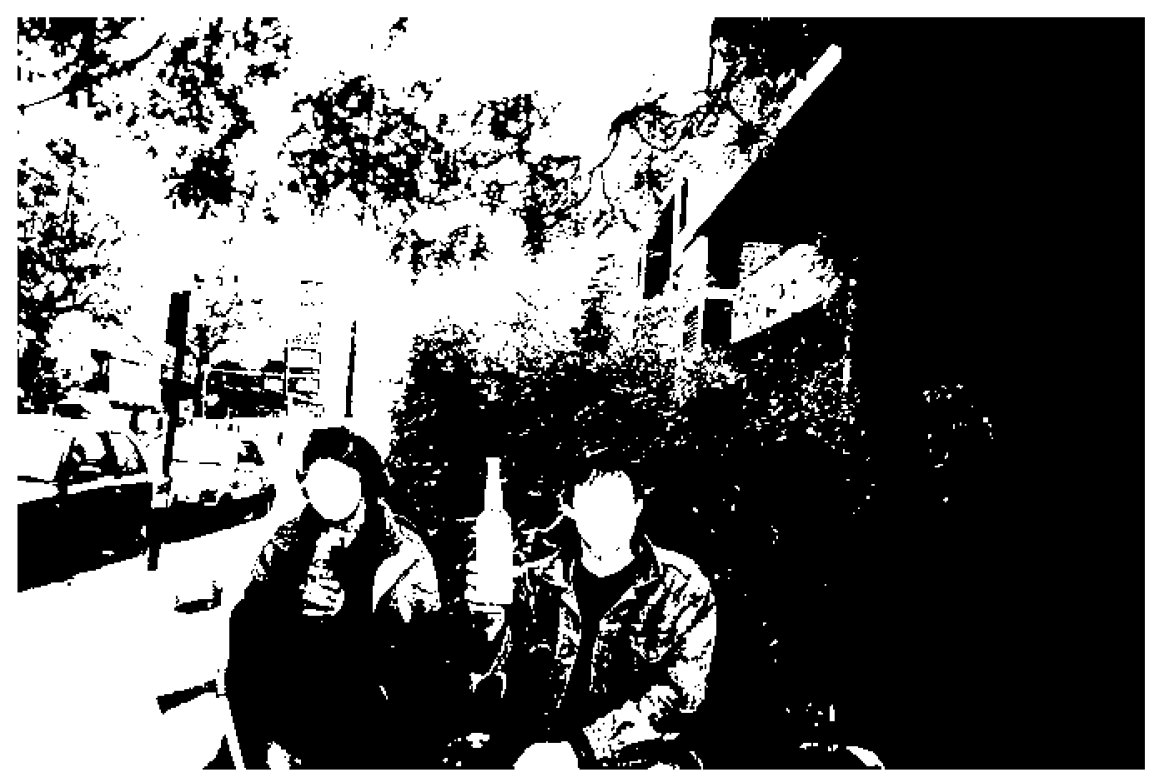

506 Figure 2 Participant depiction of a drinking school 
From reviewing media reports and the academic literature we got the impression that homeless people should be miserable and lonely. Often, many are miserable. However, these people also have fun when sharing their time on the street. These photographs are particularly significant because they depict friends enjoying the nice weather. However, because they depict homeless people drinking they can invoke negative connotations. For our participants, drinking is a communal and potentially positive activity through which group cohesion and reciprocal relationships are cultivated (Archard, 1979). It is a space for getting to know one's neighbours. These images are not produced from a domicile perspective and therefore deviate from our expectations, which construct drinking as simply a negative and disruptive activity engaged in by 'lonely old tramps'. In short, these images provide traces of the companionship, emotional support and pleasures often experienced by homeless people, but which are all but absent in the academic literature.

It would be misleading to assert that all the participants were willing to characterize themselves as members of such 'unproductive' groups, invoking social stigma. For those not asserting membership, references to these groups became a means of differentiating oneself as someone who is willing to assimilate to domicile life and expected norms regarding the use of public spaces (Atkinson, 2003). In a society that values independence and self-control (Sennett, 1998), distancing oneself from over-indulgent drinkers or users allowed many participants to foster the impression of personal restraint and similarity to members of the domicile public (Snow and Anderson, 1993). For example, when reflecting on media images of homeless people, Bob merged media portrayals with events in his own life. He referred to 'dirty rough sleepers' who did not care for themselves or the local area and who 'take drugs or drink in public places'. He reproduced a common media explanation for homelessness as being the product of lack of personal motivation and substance misuse issues, then distanced himself from these characteristics:

Well, I think a lot of people are out on the streets because they have no incentive because of their drug habit... I sometimes walk past the day centre and $I$ go over the other side of the street just to keep away from them... Some of the people who sleep out on the streets are filthy in their habits, you know. Whereas when I went out my shop door way in the morning, there wasn't even as much as a dog end in there 'cos I used to make sure I'd chuck everything out. But some of them, you've probably seen it as you walk through Victoria. There's sleeping bags lying all over the place, as filthy as anything, and they're sleeping there in them. (emphasis added)

Bob links self-respect to personal cleanliness and the proper use of space so as to not infringe on the senses of the domicile public (Atkinson, 2003). $\mathrm{He}$ is clean and in control because he does not 'let drugs take over' his life and avoids drinking schools. His account relies on differentiation from media images of rough sleepers as dirty, faceless and irresponsible 
individuals who are out of place in the city. "People think we're all like that' statements reflect a strategic reproduction of media 'us' and 'them' dichotomies that allow participants such as Bob to cross what Sibley (1995) has referred to as bounded categorizations between dirty rough sleepers and members of the domicile public. Like many of 'us', Bob even crosses the street to avoid the homeless. By situating himself as an observer of antisocial behaviour and reporting it to 'us', Bob attempts to join the judges in accusing the "others" and in the process distances himself from the dirt that is symbolic of the excluded, homeless (Sibley, 1995).

Differentiation was not the only means of exploring or challenging classifications between 'us' and 'them' or for invoking various complexities surrounding community life for homeless people. The photograph in Figure 3 was taken by Nigel to invoke the restraints imposed on homeless people's participation in enjoyable social practices.

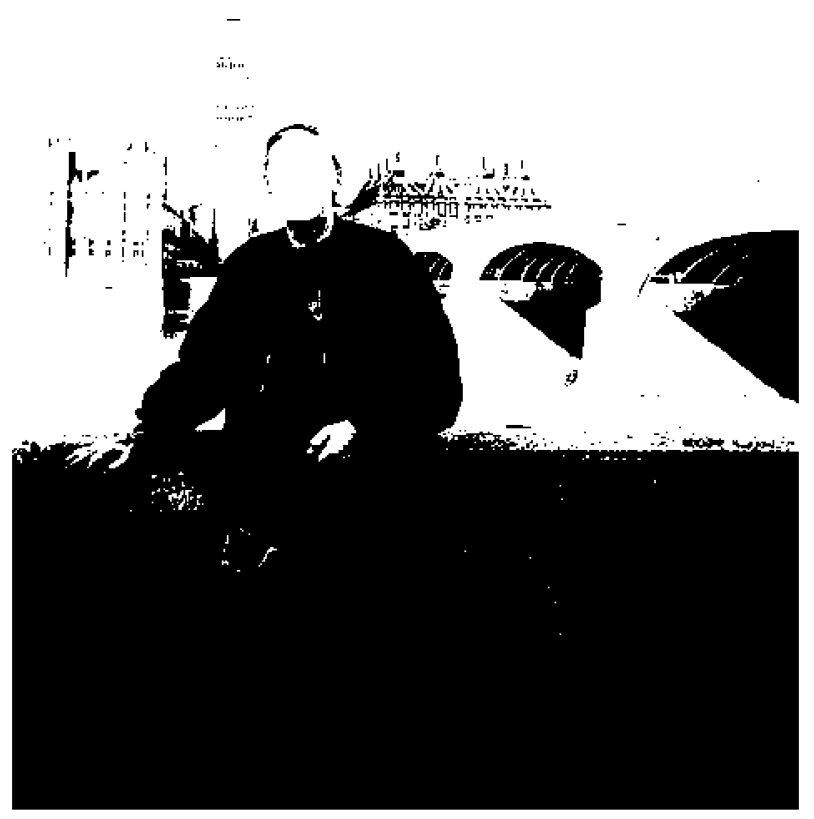

Figure 3 Participant self-portrait as a 'tourist' 
Nigel stated that the photograph 'just shows' him 'being out and about. I'm a tourist.' He took this and other photographs because he did not 'want to do a Down and Out in Paris and London-type report' (Orwell, 1933). He wanted to capture his sense of being an outsider who is excluded from activities that domicile people take for granted in London. Nigel decided to depict himself as a tourist and then use such photographs to reflect on his sense of estrangement:

It's just because it's London again, homeless again, see. The wandering around the big city, you know. I go, 'Westminster, boring'... You don't feel the same. You feel out of it when you're on the streets, going to these places... You don't feel like you're part of the tourists. You seem different from normal things in life. You get left out 'cos you're homeless . . . It sort of shows that I am not part of social life... And the only way to be part of it is by going to get yourself a flat and a job... And I think, well, that's not right. I've got a right to go and do these things, and go to Madame Tussaud's like you have, and all the rest of it. Why shouldn't I? ... But that's why I say, I dress myself to look smart and then I can go to these places.

Evident here is how the subtle investment of social spaces with rules as to who can legitimately use them can be manifested in feelings of discomfort among people who are deemed to be 'out of place' (Atkinson, 2003). Through the composition of his photograph, Nigel defends himself against any accusation that he is an unwanted intruder. Nigel attempts to translate the image of the traveller or 'boxcar rider' (Harper, 1982), who he identifies with and who is a stranger to the domicile public, into the more socially acceptable figure of the tourist. He illustrates how he can pass as just another clean, tidy, happy and unobtrusive tourist. This appropriation of the tourist shot enables Nigel to preserve his professed sense of self as a traveller while working through issues relating to his sense of place and estrangement in the metropolis. In depicting his use of tourist spaces, he raises questions regarding why homeless people are not permitted to take 'time out and enjoy themselves' in public spaces. Such appropriations of the tourist genre also enabled several participants to present themselves as being involved in a wider range of domicile activities than are associated typically with the homeless.

One does not have to question openly one's exclusion from 'normal' everyday life or public spaces in order to communicate alternative ways of being while on the street. One can challenge distinctions between 'us' and 'them' by normalizing one's existence and demonstrating the universal human desire for companionship, fun and meaningful interactions in life. To this end, several participants invoked how they often structured their days so that they could interact with domicile acquaintances and converse about more than their homelessness. They would seek out and participate in traditional neighbourhood conversations about the news events of the day. As Phillip states:

During the day in North London ... I had some nice parks and I would spend the day watching the ducks on the pond ... you know. Maybe if I'd had 
the money I'd get a bottle of cider and sort of cheer myself up, tell myself, 'Oh it could be worse.' I could have had a leg amputated and be homeless or something, you know. Sort of conning yourself in a way but you have to, otherwise you just keep down... And then as time goes by you obviously meet acquaintances, dog walkers, you know and other people. Then I'd get to know them. So I know if I went to the park at a certain time that I would be likely to meet Peter and Chris ... I was sitting there, September the 11 th ... because [of] no TV. Then Peter said, 'What about that Osama Bin Laden'? I said, 'I have no idea what you're talking about, Peter.' And then he told me about the [World] trade buildings ... They're like my TV ... Then once I was told, I found a newspaper that had been discarded. You know, it's how I keep up to date.

This extract supports the proposition that homeless people seek more than food and shelter. Such basic needs are important. However, homeless people also seek friendship, support and community. The importance of these seemingly mundane aspects of social life was raised repeatedly by the participants in a manner that highlighted the taken-for-granted function of media in providing a common ground for the conversations. Such examples reflect how media use is not necessarily about interpreting specific texts (Couldry, 2004) so much as a range of mundane activities, including 'keeping up with events', which characterize individuals as participants in community life. By invoking the September 11 attacks, Phillip illustrates his engagement with issues beyond the realm of homelessness. Evident across the participants' accounts was a sense in which homeless people did not want to be eclipsed by one material facet of their lives, no matter how influential it is for their daily lives. Participants repeatedly presented self-images of people who were not just homeless. These are community members who make choices, engage in leisure activities, shop, make mistakes, think and act and who are ultimately fallible human beings like the rest of 'us'. These people are not simply strangers. They are neighbours that one might bump into in the local park.

Such casual interactions between homeless and housed people do not simply occur in parks. They were evident when participants such as Mary discuss seemingly straightforward photographs of local businesses. Figures 4 and 5 typify how public spaces were imaged as sites for important but seemingly mundane interactions with domicile people and community participation.

Mary exemplifies the strategic use of such sites:

Mary: I think the café's very important, contact with people is very important ... There's a garage there open 24 hours. Now garages are very important to homeless people because you can buy cigarettes at night, something to eat... It keeps you going... Other than that, you have to rely on 24 hour cafés and they tend to get really crowded... This is the café in the railway station ... I have used this café since the 1980 s . . . It's a little café run by Italians . . . 


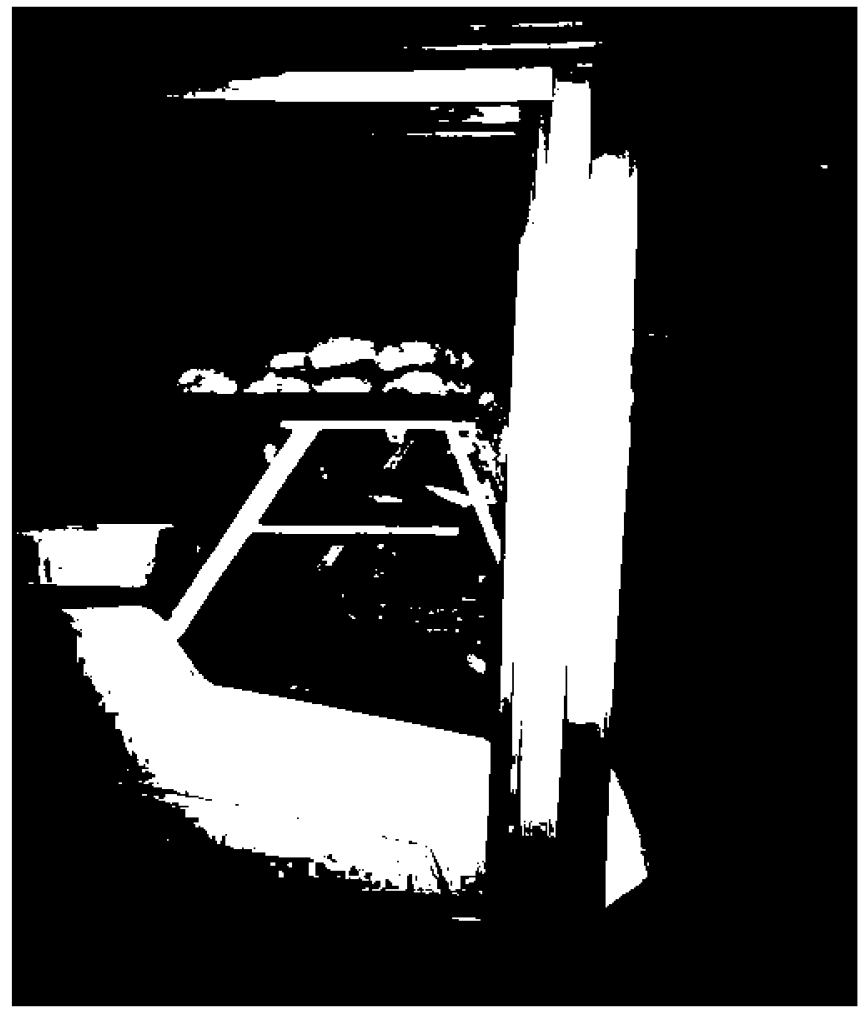

Figure 4 Participant depiction of a café as a community space

Mary: Yeah, it's a lovely picture and they've been an absolute lifeline. They serve teas at $60 \mathrm{p}$, which is quite cheap. You can get meat pies for a pound which is very nice... Also, it's somebody to chat to, you know ... They get to know you... Not long chats because they're busy with customers, but you do tend to get the odd little chat, which brings you back to reality 'cos when you've spent hours and hours walking round the street on your own you do tend to go off into a dream world.

Like Nigel and Phillip, Mary related her search for links with the local community with the experience of loneliness and exclusion on the street that arose from her desire not to engage with homeless groups. Participation in the wider community and enjoyable aspects of life was a core element of many participants' accounts. Regular 'you know' statements invoked the mundane nature of going to a café and repositioned participants such as Mary as engaging in similar leisure activities to members of the local domicile community. Such statements support claims to participation and normality. Further, seeking community ties in parks, coffee shops, garages, theatres, libraries, bookmakers" shops, fish and chip shops and grocery stores appears to constitute attempts to maintain one's dignity as a person who is recognized and who belongs (Miller and Keys, 2001). 


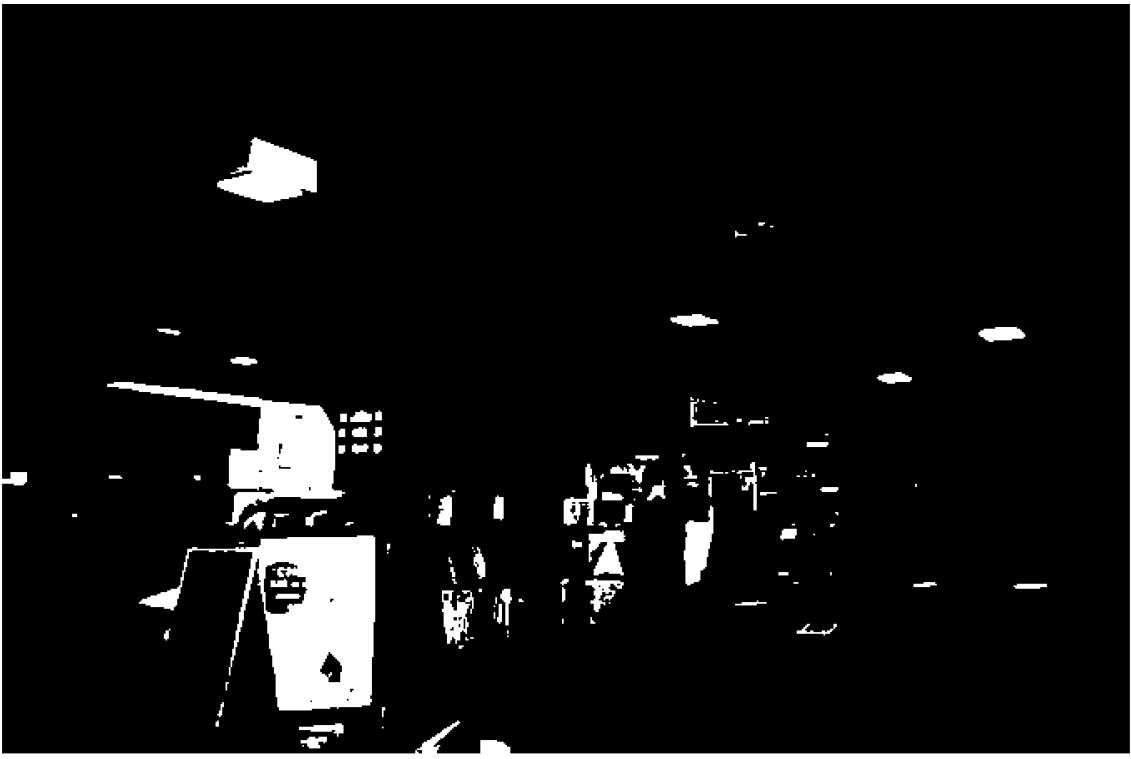

Figure 5 Participant depiction of a service station as a community space

Consumption is a core element of participation in the capitalist city (Sennett, 1998). It should not be surprising then when homeless people emphasize the importance of consumption and participation when making claims to community membership. Mary preserves her sense of self and participation in society through accounts of the consumption of cigarettes, coffee, tea, chocolate and pies, engagements in mundane practices such as shopping and stopping for a coffee and a chat. Being clean and tidy due to the services of charities such as The Passage day centre and Graham House ensured that participants were able to become customers who frequented cafés, local stores, pubs, gambling shops and tourist sites. In short, these participants did not merely occupy public spaces, but could lay claim to them as local users, if only tentatively (see Atkinson, 2003). Participants claimed to belong when they consumed in socially sanctioned ways and illustrated lives where they tried (with some success) to pass for domicile persons.

Although seeking interaction with members of local communities can provide rewarding experiences and serve as a basis for a sense of belonging, it is not always a universally positive experience. Expressions of vulnerability in claims of local residency or belonging comprised a core element of the biographical accounts of participants such as Mary:

Mary: It's very lonely, because a lot of the times you're frightened to speak to people and tell them your situation... Let me give you an example. There's a company ... who, the chap there, he used to open the door and give me a few pennies, you know. As much as five pounds once and recently I knocked 
on his door because I do some drawings for him ... which he did say he was interested in. But ... this particular day he just turned round to his colleague and said, 'Don't worry, she's just an old beggar lady' and he threw some coins at me. And that was dreadful ...

Andrea: How do you feel about that?

Mary: Well, I don't think that I am what they say I am. I don't think I am a bag lady ... I thought that people in general they love to categorize. You belong there, you belong there...

Recounting this instance foregrounds how attempts to preserve personal dignity and self-respect can be fragile undertakings because homeless people's sense of belonging is open to question and can be ruptured through the imposition of mediated characterizations, which include the 'bag lady'. Jarvinen (2003) found that the accounts of homeless people reflected a sense of defensiveness because they were constantly on trial and their membership to communities is often at risk. The accounts reflect feelings of 'abjection' or, as Sibley (1995: 78) notes, 'a heightened consciousness of difference', in this case associated with the reimposition of boundaries between homeless and domiciled people which result in the exclusion of homeless people. Thus, a key to understanding the implications of this man calling Mary a 'beggar lady' is reflected in the wider intergroup relations and representational practices between homeless and domicile groups (Snow and Mulcathy, 2001). Domicile people have the symbolic power to impose their expectations and characterizations on the homeless. The distinction between social and felt identities (Snow and Anderson, 1993) is useful in unravelling the social significance of this imposition. Social identities constitute mediated characterizations of homeless people that are constructed by various political and professional groups. Felt identities are constructed in response to social identities by rough sleepers themselves. A sense of self for the participants was constructed through the tensions between these identity formations. Mary felt aggrieved when described as a 'beggar lady' because this accusation broke through her attempt to project an alternative identity as a 'normal' and therefore legitimate community member. The instance described above stripped her of personal dignity (Miller and Keys, 2001), rupturing her attempt to broaden out her sense of self beyond the shallow characterization of the 'bag lady' promoted through media representations (see Champaign, 1999).

\section{Discussion}

Previous research provides valuable insights into the negative impact of homelessness for people's health and welfare (Boydell et al., 2000; Snow and Anderson, 2003). However, research has not adequately addressed the links between material deprivation and symbolic power (Couldry and Curran, 2002). We have extended the research into how media coverage 
can preserve collective explanations for homelessness that can be harmful to vulnerable people (Hodgetts et al., 2005) by engaging with the processes through which media imaging practices exert an influence on the lives of rough sleepers in London. Specifically, we set out to document how people who happen to be homeless forge places on the edge of society through the use of media representations. We have shown that homeless people do not simply reproduce prefabricated characterizations, but rather appropriate media depictions when articulating a personal sense of self and place. These homeless people are well aware of how the symbolic power concentrated in media institutions influences their lives through the cultivation of public accusations. They invoke a profound sense of being on trial and subject to estrangement and emphasize the need to exist outside the confines of mediated expectations in order to preserve a sense of personal dignity and community participation.

Despite the restraining influence of media framing on what the participants showed and told us, the mediated resources only provided a starting point from which they began to resist the detectable features of the stranger and negotiate their own images. Their photographs recorded lives as they are lived, not solely as they are pre-scripted according to media representations. This involved a conscious manipulation of the codes of representation in which friendship and group solidarity as well as strong personal identity were forcefully expressed' (Dewdney et al., 1994: 118). The participants focused on expressing the mundane practices of domicile existence in order to self-represent as 'normal' people (see Champaign, 1999). In the process, the practices central to the avoidance of mediated social identities in favour of localized felt identities became apparent (Couldry, 2004; Snow and Anderson, 1993).

In exploring such sense-making practices we have been influenced by cultural studies work on symbolic resistance (Couldry, 2001; Fiske, 1999). Rather than approaching marginalized groups as simply victims of oppression and social inequalities, the focus shifts to 'cultures of resistance" or the strategies through which groups such as rough sleepers work to construct alternative meanings and ways of being (Couldry and Curran, 2002). The focus is on expressions of personal agency, where homeless people use aspects of media representations to construct their own images and resist estrangement. It is necessary to point out that homeless people are not always assertive in resisting negative representations. They are often demoralized and subdued (Boydell et al., 2000; Snow and Anderson, 1993). However, by focusing on the active role of homeless participants in making sense of their own lives we have exemplified how marginalized citizens actively imagine themselves and tell the story of their lives in the shadow of the media. 


\section{Acknowledgements}

This project was funded by a grant from Santory and Toyota Centres for Economics and Related Disciplines at the London School of Economics and at the report stage by a British Academy International Joint Activities Award. We would like to thank the staff from Thames-Reach Bondway and The Passage for their contributions to the project.

\section{Note}

1. All participants are identified using pseudonyms.

\section{References}

Anderson, B. (1991) Imagined Communities: Reflections on the Origin and Spread of Nationalism. London: Verso.

Archard, P. (1979) Vagrancy, Alcoholism and Social Control. London:

Macmillan.

Atkinson, R. (2003) 'Domestication by Cappuccino or a Revenge on Urban Space? Control and Empowerment in the Management of Public Spaces', Urban Studies 40(9): 1829-43.

Blumler, J. (1969) Symbolic Interactions: Perspectives and Methods. Englewood Cliffs, NJ: Prentice Hall.

Boydell, K.M., P. Goering and T.L. Morrell-Bellai (2000) 'Narratives of Identity: Representation of Self in People Who Are Homeless', Qualitative Health Research 10(1): 26-38.

Champaign, P. (1999) 'The View from the Media', in P. Bourdieu, A. Accardo, G. Balazs, S. Beaud, F. Bonvin, E. Bourdieu, P. Bourgois, S. Broccolichi, P. Champaign, R. Christin, J.P. Faguer, S. Garcia, R. Lenoir, F. Euvrard, M. Pialoux, L. Pinto, D. Podalydès, A. Sayad, C. Soulié and L. Wacquant (eds) The Weight of the World: Social Suffering in Contemporary Society (trans. P. Ferguson, S. Emanuel, J. Johnson and S.T. Waryn), pp. 46-59. Cambridge: Polity Press.

Clapham, D. (2003) 'Pathways Approaches to Homelessness Research', Journal of Community and Applied Social Psychology 13(1): 119-27.

Couldry, N. (2001) 'The Umbrella Man: Crossing a Landscape of Speech and Silence', Cultural Studies 4(2): 131-52.

Couldry, N. (2004) 'Theorising Media as Practice', Social Semiotics 14: 115-32. Couldry, N. and J. Curran (eds) (2002) Contesting Media Power: Alternative Media in a Networked World. New York: Rowman and Littlefield. Dewdney, A., C. Grey and A. Minnion (1994) Down But Not Out: Young People, Photography and Images of Homelessness. Stoke-on-Trent: Trentham Books.

Fiske, J. (1999) 'For Cultural Interpretation: A Study of the Culture of Homelessness', in E. Min (ed.) Reading the Homeless: The Media's Image of Homeless Culture, pp. 1-22. London: Praeger.

Harper, D. (1982) Good Company. Chicago, IL: University of Chicago Press. Hodgetts, D., A. Cullen and A. Radley (2005) 'Television Characterizations of Homeless People in the United Kingdom', Analyses of Social Issues and Public Policy 5(1): 29-48.

Jarvinen, M. (2003) 'Negotiating Strangerhood: Interviews with Homeless Immigrants in Copenhagen', Acta Sociologica 46(3): 215-30. 
Madden, M. (2003) 'Braving Homelessness on the Ethnographic Street with Irene Glasser and Rae Bridgman', Critique of Anthropology 23(3): 289-304.

Miller, A. and C. Keys (2001) 'Understanding Dignity in the Lives of Homeless Persons', American Journal of Community Psychology 29(2): 331-54.

Min, E. (ed.) (1999) Reading the Homeless: The Media's Image of Homeless Culture. London: Praeger.

Orwell, G. (1933) Down and Out in Paris and London. London: Gollancz.

Radley, A., D. Hodgetts and A. Cullen (2005) 'Visualising Homelessness: A Study of Photography and Estrangement', Journal of Community and Applied Social Psychology 15(4): 273-95.

Sennett, R. (1998) The Corrosion of Character. London: W.W. Norton \& Co. Sibley, D. (1995) Geographies of Exclusion. Routledge: London.

Silverstone, R. (1999) Why Study the Media? London: Sage.

Simmel, G. (1908) 'The Stranger', in D. Levine (ed.) Georg Simmel. On Individuality and Social Forms, pp. 143-9. Chicago, IL: Chicago University Press.

Snow, D.A. and L. Anderson (1993) Down on Their Luck: A Study of Homeless Street People. Berkeley: University of California Press.

Snow, D. and M. Mulcathy (2001) 'Space, Politics and the Survival Strategies of the Homeless', American Behavioral Scientist 45(1): 149-69.

'Street Life Stuck in Victorian Era' (2005) The Times (29 Nov.). [Available at: http://www.timesonline.co.uk/printFriendly/0:, 1-8247-1893494-8247:00. html]

\section{Biographical notes}

Darrin Hodgetts is a senior lecturer in community psychology at the University of Waikato where he teaches courses in community health and media psychology and researches social disadvantage. He has held teaching and research positions in community health at Memorial University, Canada and media and communications at the London School of Economics and Political Sciences. A DDRESS: University of Waikato, Private Bag 3105: Hamilton, New Zealand. [email: dhdgetts@waikato.ac.nz]

Andrea Hodgetts is a clinical psychologist who researches lower socio-economic groups' experiences of unemployment, homelessness and sexual abuse. Currently she is working on government-sponsored research which informs the development of best practice guidelines for sexual abuse/assault clients in New Zealand.

Alan Radley is founding editor of Health: An Interdisciplinary Journal for the Social Study of Health, Illness and Medicine. Apart from work on homelessness, his current research interests focus upon the aesthetics of illness and the use of visual methods in this context. 